SUBJECT AREAS:

HAIR CELL

INNER EAR

GENE REGULATION

Received

18 August 2014

Accepted

13 October 2014

Published

3 November 2014

Correspondence and requests for materials should be addressed to J.Z. (jian.zuo@stjude. \title{
mice: a tool for inducible gene expression in hair cells of the inner ear
}

\author{
Brandon C. Cox ${ }^{1,2,3}$, Jennifer A. Dearman ${ }^{3}$, Joseph Brancheck' ${ }^{1}$, Frederique Zindy ${ }^{4}$, Martine F. Roussel ${ }^{4}$ \\ \& Jian $\mathrm{Zuo}^{3}$
}

'Department of Pharmacology, Southern Illinois University, School of Medicine, Springfield, IL 62702, ${ }^{2}$ Department of Surgery,
Division of Otolaryngology, Southern Illinois University, School of Medicine, Springfield, IL 62702, ${ }^{3}$ Department of Developmental
Neurobiology, St. Jude Children's Research Hospital, Memphis, TN 38105, 4 Department of Tumor Cell Biology. St. Jude Children's Research Hospital, Memphis, TN 38105.

Atoh1 is a basic helix-loop-helix transcription factor that controls differentiation of hair cells (HCs) in the inner ear and its enhancer region has been used to create several HC-specific mouse lines. We generated a transgenic tetracycline-inducible mouse line (called Atoh1-rtTA) using the Atoh1 enhancer to drive expression of the reverse tetracycline transactivator (rtTA) protein and human placental alkaline phosphatase. Presence of the transgene was confirmed by alkaline phosphatase staining and rtTA activity was measured using two tetracycline operator (TetO) reporter alleles with doxycycline administered between postnatal days $0-3$. This characterization of five founder lines demonstrated that Atoh1-rtTA is expressed in the majority of cochlear and utricular HCs. Although the tetracycline-inducible system is thought to produce transient changes in gene expression, reporter positive HCs were still observed at 6 weeks of age. To confirm that Atoh1-rtTA activity was specific to Atoh1-expressing cells, we also analyzed the cerebellum and found rtTA-driven reporter expression in cerebellar granule neuron precursor cells. The Atoh1-rtTA mouse line provides a powerful tool for the field and can be used in combination with other existing Cre recombinase mouse lines to manipulate expression of multiple genes at different times in the same animal.

\footnotetext{
C onditional gene expression enables the temporal study of genes during development and in adulthood. This method also allows for cell-type specific gene manipulation and alleviates embryonic lethality which can occur when certain genes are overexpressed or deleted in the germline. The Cre-mediated recombination system (Cre/loxP) is the most common method to delete or ectopically express genes in a cell-type specific manner, with temporal control of gene expression achieved by fusion of Cre recombinase with a modified tamoxifen-inducible estrogen receptor (CreER ${ }^{\mathrm{TM}}$ or $\mathrm{CreER}^{\mathrm{T} 2}$ ) (reviewed $\mathrm{in}^{1}$ ). Tetracycline-inducible mouse models (Tet-On or Tet-Off) can also be used for conditional gene expression and in contrast to Cre/loxP, gene expression changes are transient ${ }^{2,3}$. In some cases one needs to manipulate expression of multiple genes in two different cell types or in the same cell type but at different ages. This can be achieved by combining Cre/loxP and tetracycline-inducible mouse models. Unfortunately there are few tetracycline-inducible mouse lines with celltype specific expression available, thus warranting the development of new models.

The Tet-On system uses a reverse tetracycline transactivator (rtTA) protein that binds to the promoter and activates transcription of a second transgene which contains a tetracycline operator (TetO). The rtTA protein can only bind to TetO and activate transcription in the presence of doxycycline (a more potent analogue of tetracycline). Once doxycycline is removed, transcription will cease since rtTA can no longer bind to TetO, allowing for transient control of gene expression (Figure 1A) (2,3 $^{2}$. Cell-type specific expression can be achieved using specific promoters or enhancers to express the rtTA protein. This mechanism is distinct from the Cre/loxP system, and thus the two methods of conditional gene expression can be combined.

Atoh1, also called Math1 in mice, is the mammalian homolog of the Drosophila gene, atonal, and is a basic helix-loop-helix transcription factor that controls differentiation of hair cells (HCs) in the inner ear ${ }^{4}$ and proliferation of granule neuron precursor cells in the cerebellum ${ }^{5}$. The $1.7 \mathrm{~kb}$ enhancer element located in the $3^{\prime}$ untranslated region of Atoh $1^{6}$ has been used to generate several mouse lines: Atoh1-Cre ${ }^{7}$, Atoh1-CreER ${ }^{T M, 8}$, Atoh1$\mathrm{CreER}^{T 2,9}$, and Atoh1-eGFP ${ }^{10}$. Because each of these mouse models has Cre or eGFP expression in HCs and
} 


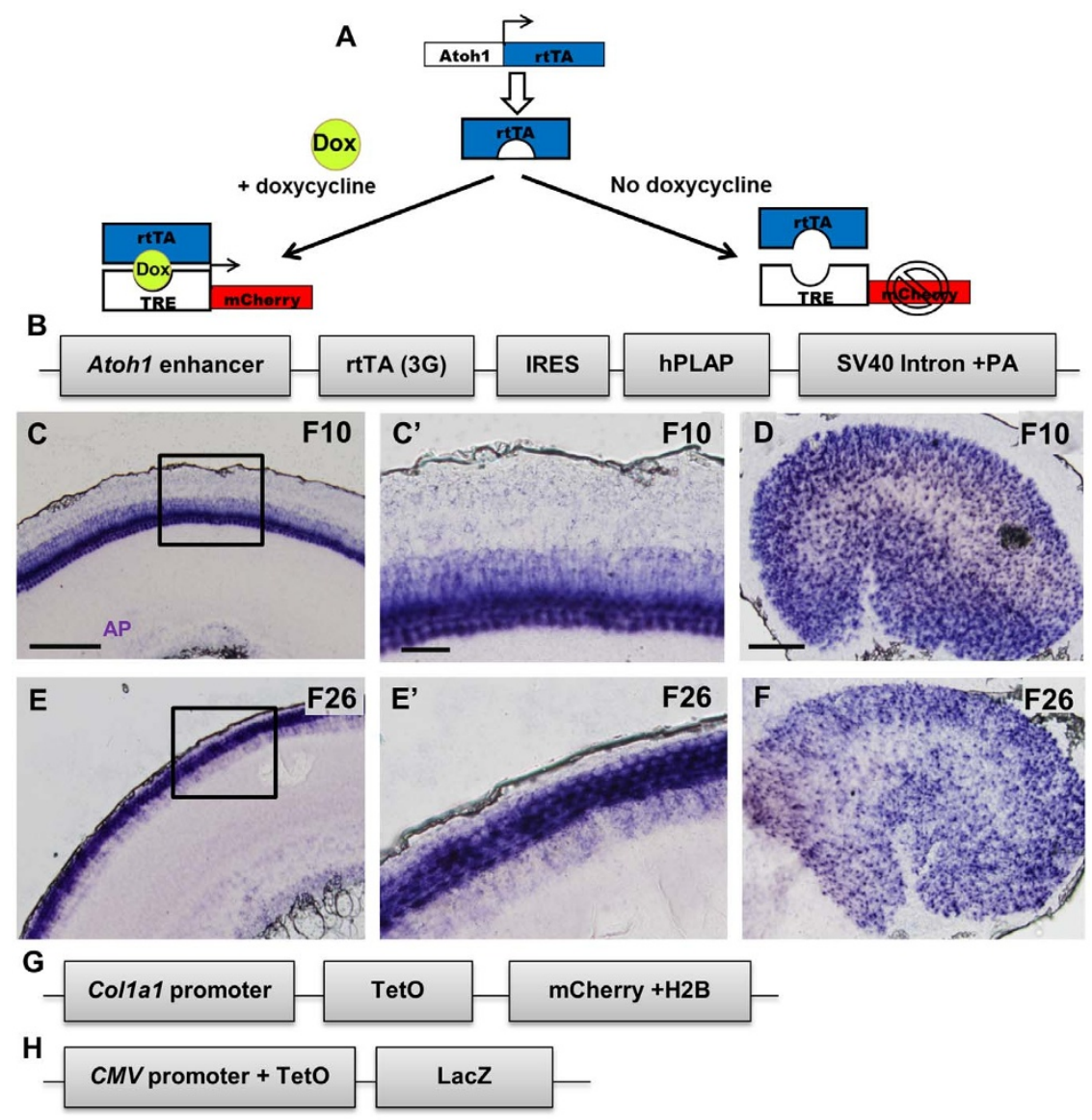

Figure $1 \mid$ Components of the Tet-On system and alkaline phosphatase staining. (A) Diagram explaining the Tet-On system. (B) Modified Atoh1CreER-IRES-hPLAP-SV40 Intron- polyadenylation construct ${ }^{8}$ showing replacement of the CreER sequence with the $3 G r t T A$ sequence. Representative alkaline phosphatase (AP) staining images of F10 and F26 showing the presence of the Atoh1-rtTA transgene in the apical turn of the P0 cochlea (C, E) and utricle (D, F). ( $\mathrm{C}^{\prime}$ and $\left.\mathrm{E}^{\prime}\right)$ High magnification images of region labeled by the black squares in $(\mathrm{C})$ and $(\mathrm{E})$. Scale bars: $100 \mu \mathrm{m}$ in $(\mathrm{C}-\mathrm{F})$ and $20 \mu \mathrm{m}$ in $\left(\mathrm{C}^{\prime}\right)$ and $\left(\mathrm{E}^{\prime}\right)$. Schematic of the TetO-mCherry $(\mathrm{G})$ and TetO-LacZ $(\mathrm{H})$ reporter alleles.

cerebellar granule cells, we used the same enhancer element to generate a HC-specific Tet-On mouse model. Here, we describe the generation and characterization of an Atoh1-rtTA mouse line in the inner ear.

\section{Results}

The CreER sequence in the Atoh1-CreER-internal ribosome entry site (IRES)-human placental alkaline phosphatase (hPLAP)-SV40 intronpolyadenylation construct (Atoh1-CreER-IRES-hPLAP-SV40-polyA) was replaced with a $3 G r t T A$ (Figure $1 \mathrm{~B})$. This $3^{\text {rd }}$ generation rtTA has reduced levels of basal expression and increased sensitivity to doxycycline compared to Tet-On and Tet-On Advanced systems ${ }^{11}$. After pronuclear injection, seven founders were produced and the presence of the transgene was confirmed by Southern blot and PCR analysis. All founders went through germline transmission. However, two founder lines did not breed well; thus we assessed rtTA activity in five founder lines (F7, F10, F12, F23, and F26), each of them showing expression of hPLAP in HCs of the cochlea and utricle at postnatal day (P) 0 (Figure $1 \mathrm{C}-\mathrm{F}$ ).

We used two rtTA reporter alleles since their reporter activity varied. The TetO-mCherry reporter is a knock-in allele where the TetO element and mCherry coding sequence fused to histone $\mathrm{H} 2 \mathrm{~B}$ were inserted downstream of the endogenous collagen type 1, alpha 1 (Col1a1) promoter (Figure 1G) ${ }^{12}$. This reporter is robust since the Colla1 promoter is strongly expressed in epithelial cells ${ }^{13}$, and the mCherry molecule provides bright endogenous fluorescence that is photostable $^{14}$. In contrast, the TetO-LacZ reporter is a transgenic allele where $L a c Z$ is under the control of the human cytomegalovirus early promoter (CMV) fused to the TetO element (Figure $1 \mathrm{H})^{15}$. $\mathrm{LacZ}$ expression is variable, requiring $\mathrm{X}$-gal staining or an anti- $\beta$ galactosidase ( $\beta$ gal) antibody for detection.

Reporter alleles were first tested for basal activity at P3 with TetOreporter $^{+v e}$ mice administered doxycycline between $\mathrm{P} 0-\mathrm{P} 3$, but in the absence of the $r t T A$ allele. In TetO- $m$ Cherry ${ }^{+v e}$ mice, no mCherry $^{+v e}$ cells were seen in the sensory region of the cochlea or utricle (Figure 2A, B). However there was an apical-to-basal gradient of increasing $\mathrm{mCherry}^{+\mathrm{ve}}$ cells in the spiral ganglion (SGN) region of the cochlea (Figure $2 \mathrm{~A}-\mathrm{A}^{\prime}$ ) as well as several mCherry ${ }^{+v}$ cells in the utricular stroma (Figure $2 \mathrm{~B}^{\prime}$ ). In TetO-LacZ ${ }^{+\mathrm{ve}}$ mice, no $\mathrm{LacZ}^{+\mathrm{ve}}$ cells were observed in the cochlea or SGN; however, in the utricle, several $\mathrm{LacZ}^{+\mathrm{ve}}$ supporting cells (SCs) were observed, but no HCs or stromal cells were labeled (Figure $2 \mathrm{C}-\mathrm{C}^{\prime \prime}$ ). The presence of reporter ${ }^{+\mathrm{ve}}$ cells in the absence of the rtTA protein has been reported previously in other organ systems ${ }^{15}$.

We also tested for leakiness of rtTA activity in the absence of doxycycline using Atoh1-rtTA ${ }^{+v e}$; TetO-mCherry ${ }^{+v e}$ or Atoh1$r t T A^{+\mathrm{ve}}$; TetO-Lac $\mathrm{Z}^{+\mathrm{ve}}$ mice from the F7 lineage analyzed at P3. No mCherry ${ }^{+v e}$ cells were observed in the sensory regions of the cochlea or utricle; however, there was an apical-to-basal gradient of increasing mCherry $^{+v e}$ cells in the SGN region (Figure $2 \mathrm{D}-\mathrm{D}^{\prime}$ ) and mCherry $^{+\mathrm{ve}}$ cells in the utricular stroma (Figure $2 \mathrm{E}-\mathrm{E}^{\prime}$ ), similar to the basal activity seen in TetO-mCherry ${ }^{+\mathrm{ve}}$ controls that received doxycycline but lacked the $r t T A$ allele (Figure $2 \mathrm{~A}-\mathrm{B}^{\prime}$ ). No $\mathrm{LacZ}^{+\mathrm{ve}}$ cells were detected in Atoh1-rtTA ${ }^{+\mathrm{ve}} ;$ TetO-LacZ ${ }^{+\mathrm{ve}}$ cochleae 

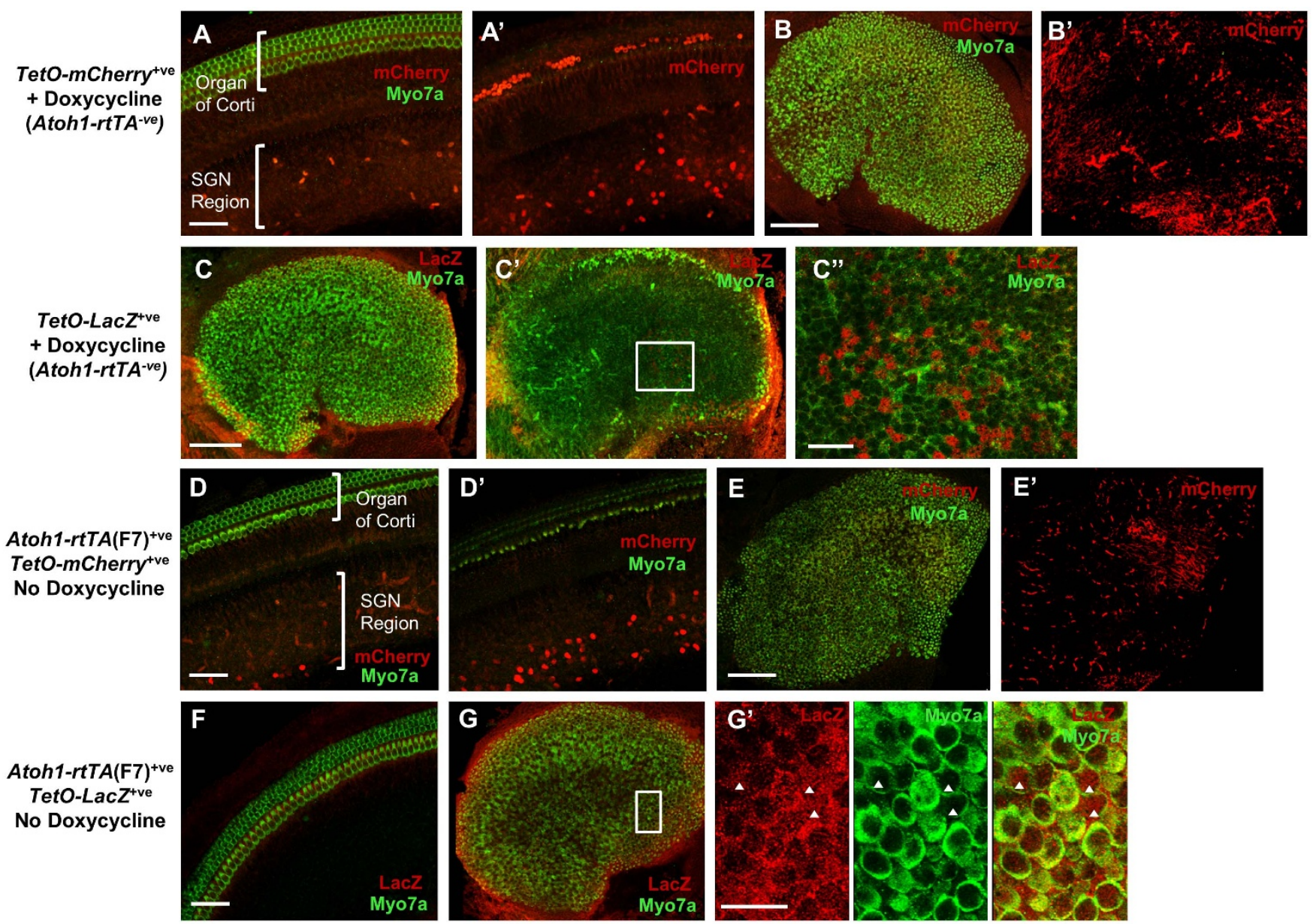

Figure $2 \mid$ Basal activity of TetO-reporters and Atoh1-rtTA(F7) activity in the absence of doxycycline. Representative confocal images of a TetO$m$ Cherry $^{+v e}\left(\right.$ Atoh1-rtTA $\left.{ }^{-v e}\right)$ control cochlea $\left(\mathrm{A}-\mathrm{A}^{\prime}\right)$ and utricle $\left(\mathrm{B}-\mathrm{B}^{\prime}\right)$ at $\mathrm{P} 3$ from mice that were administered doxycycline to test for basal expression of the TetO-mCherry reporter. mCherry ${ }^{+v e}$ cells were detected in the SGN region of the cochlea $\left(\mathrm{A}-\mathrm{A}^{\prime}\right)$ and in the utricular stroma (B-B'). Note in $\mathrm{A}^{\prime}$ the labeled cells in the organ of Corti are red blood cells. No mCherry ${ }^{+v e}$ cells were detected in the sensory region of either the cochlea or utricle. (C-C') Representative confocal images of a TetO-Lac $Z^{+v e}\left(\right.$ Atohl-rtTA ${ }^{-v e}$ ) control utricle at $\mathrm{P} 3$ from mice that were administered doxycycline to test for basal expression of the TetO-LacZ reporter. Some LacZ ${ }^{+v e}$ SCs but no LacZ ${ }^{+v e} \mathrm{HCs}$ were detected. $\left(\mathrm{C}^{\prime \prime}\right)$ High magnification images of the region outlined by the white square in $\mathrm{C}^{\prime}$. Representative confocal images of an un-induced Atoh1-rtTA(F7) $)^{+\mathrm{ve}}$; TetO-mCherry ${ }^{+\mathrm{ve}}$ control cochlea $\left(\mathrm{D}-\mathrm{D}^{\prime}\right)$ and utricle $\left(\mathrm{E}-\mathrm{E}^{\prime}\right)$ at P3 that did not receive doxycycline. mCherry ${ }^{+v e}$ (red) cells were detected in the SGN region of the basal turn of the cochlea (D-D') and in the urticular stroma $\left(E-E^{\prime}\right)$. No mCherry ${ }^{+v e}$ cells were detected in the sensory region of either the cochlea or utricle. Representative confocal image of an un-induced Atoh1-rtTA(F7) ${ }^{+v e}$; TetO-LacZ ${ }^{+v e}$ control cochlea (F) and utricle $\left(\mathrm{G}_{-} \mathrm{G}^{\prime}\right)$ at P3 that did not receive doxycycline. Several HCs (myo7a ${ }^{+\mathrm{ve}}$, green) expressed LacZ (red) in the medial region of the utricle $\left(G-G^{\prime}\right)$ and no LacZ ${ }^{+v e}$ cells were detected in the cochlea (F). ( $\left.G^{\prime}\right)$ High magnification image of the region outlined by the white square in $(\mathrm{G})$. Arrowheads denote LacZ ${ }^{+v e} \mathrm{HCs}$. Myo7a (green) was used to label HCs in most panels. Scale bar: $50 \mu \mathrm{m}$ in $\left(\mathrm{A}-\mathrm{A}^{\prime}\right)$, $\left(\mathrm{D}-\mathrm{D}^{\prime}\right)$, and $(\mathrm{F}), 100 \mu \mathrm{m}$ in $\left(\mathrm{B}-\mathrm{C}^{\prime}\right),(\mathrm{E})$, and $(\mathrm{G})$, and $20 \mu \mathrm{m}$ in $\left(\mathrm{C}^{\prime \prime}\right)$ and $\left(\mathrm{G}^{\prime}\right)$.

(Figure 2F), while in the utricle some LacZ ${ }^{+v e}$ SCs were observed and a small percentage of $\mathrm{HCs}$ in the medial region were $\mathrm{LacZ}^{+\mathrm{ve}}$ (Figure 2G-G').

Each of the Atoh1-rtTA founder lines was bred with a TetO$m$ Cherry or a TetO-LacZ reporter mouse and double-transgenic offspring (Atoh1-rtTA ${ }^{+\mathrm{ve}}$; TetO-reporter ${ }^{+\mathrm{ve}}$ ) administered doxycycline between P0-P3 were evaluated at P3 for rtTA activity. The five Atoh1-rtTA founders bred with the TetO-mCherry reporter showed robust expression of $\mathrm{mCherry}^{+\mathrm{ve}}$ cochlear HCs: F7 $=99.6$ $\pm 0.1 \%, \mathrm{~F} 10=99.7 \pm 0.2 \%, \mathrm{~F} 12=98.2 \pm 0.4 \%, \mathrm{~F} 23=69.6 \pm$ $11.5 \%$, and $\mathrm{F} 26=94.4 \pm 1.6 \%$ (mCherry $^{+\mathrm{ve}} \mathrm{HCs}$ expressed as a percentage of total HCs, $n=3$, Figure $3 \mathrm{~A}-\mathrm{E}^{\prime}, \mathrm{K}$ ). There was no significant difference in the number of $\mathrm{mCherry}^{+\mathrm{ve}}$ cells between inner and outer HCs or across cochlea turns for any founder line. In addition, the intensity of the mCherry reporter was very consistent across all turns of the cochlea and in all founders (Figure $3 \mathrm{~A}-\mathrm{E}^{\prime}$ ). However, there were variations in the cell typespecificity of mCherry expression (Table 1). F26 was the only founder in which mCherry expression was specific to HCs. F7, F10, and F23 each had mCherry ${ }^{+v e}$ HCs in all turns of the cochlea. In apical and middle turns, mCherry expression was only observed in HCs. However in the basal turn of these founders, there were some mCherry ${ }^{+v e}$ inner phalangeal cells (IPhCs) (a SC subtype that surrounds inner HCs) and a few mCherry ${ }^{+v e}$ cells in the greater epithelial ridge (GER). Lastly, F12 had HC-specific mCherry labeling only in the apex. In addition to mCherry ${ }^{+v e}$ HCs, the middle turn had few mCherry ${ }^{+v e}$ IPhCs, which increased in number in the basal turn.

The cochlea of Atoh1-rtTA; TetO-LacZ mice also showed variability among the five founders: F7 $=77.0 \pm 11.0 \%$, F10 $=85.8 \pm 3.3 \%$, $\mathrm{F} 12=84.1 \pm 4.6 \%, \mathrm{~F} 23=63.5 \pm 6.8 \%$, and $\mathrm{F} 26=78.7 \pm 2.8 \%$ $\left(\mathrm{LacZ}^{+\mathrm{ve}} \mathrm{HCs}\right.$ expressed as a percentage of total HCs, $n=3-4$, Figure $\left.3 \mathrm{~F}-\mathrm{J}^{\prime}, \mathrm{L}\right)$. There was no significant difference in the number of LacZ ${ }^{+\mathrm{ve}}$ cells between inner and outer HCs or across cochlear turns in any founder. All founders had LacZ expression in other cells besides HCs (Table 1). In F7 and F26, LacZ expression was the most 

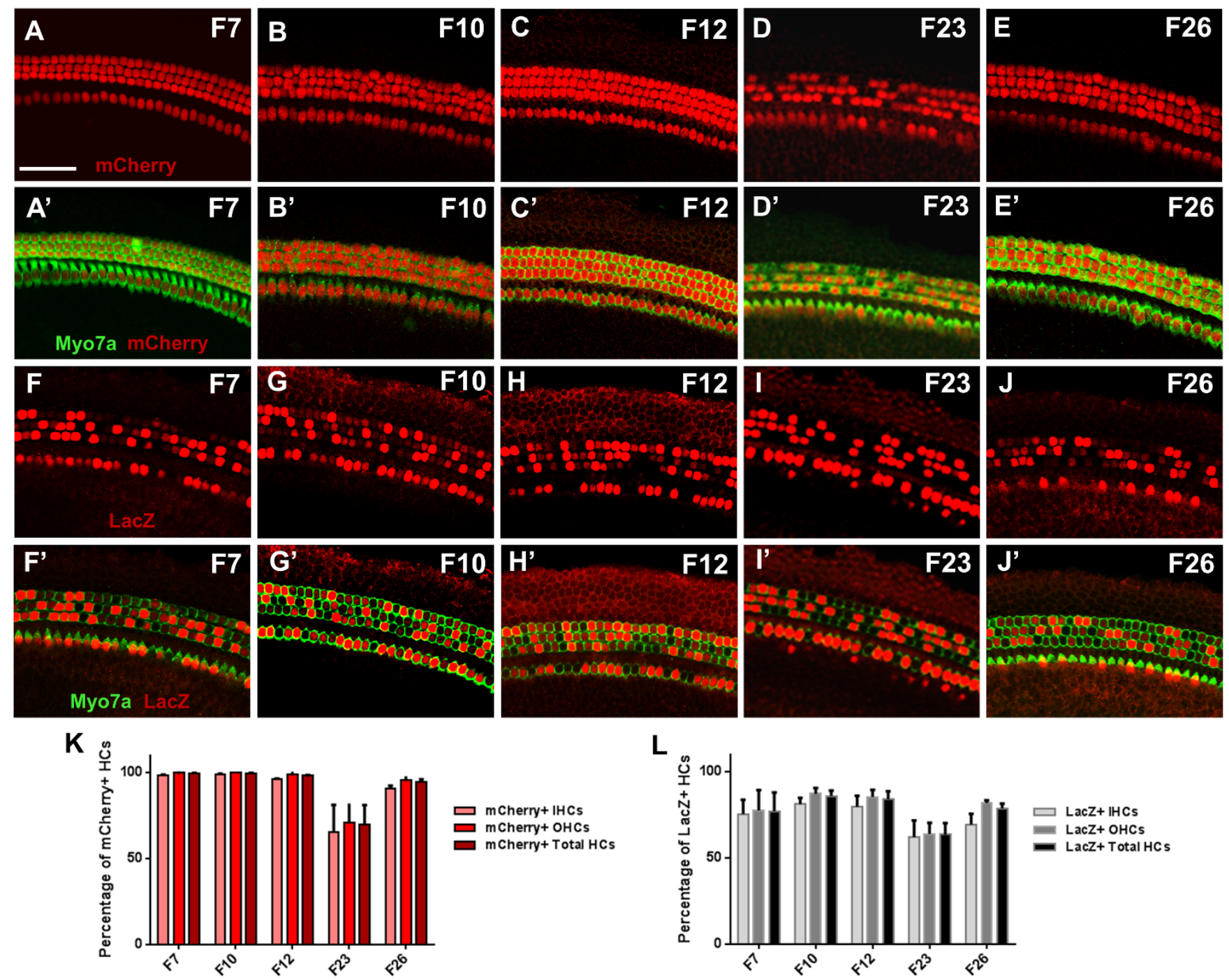

Figure 3 | Atoh1-rtTA activity in the cochlea. Representative confocal images of mCherry ${ }^{+ \text {ve }}$ (red) cells in the middle turn of each founder line breed with the TetO-mCherry reporter at P3 (A-E) and corresponding merged images where HCs were labeled with myosin VIIa (Myo7a, green) (A'-E'). Representative confocal images of $\mathrm{LacZ}^{+ \text {ve }}$ (red) cells in the middle turn of each founder line breed with the TetO-LacZ reporter at P3 (F-J) and corresponding merged images where HCs were labeled with Myo7a (green) $\left(\mathrm{F}^{\prime}-\mathrm{J}^{\prime}\right)$. (K) Percentage of Myo7a $\mathrm{a}^{+\mathrm{ve}}$ cells that express $\mathrm{mCherry}$ in each founder line, normalized to the number of total Myo7a ${ }^{+v e}$ cells in the same region. (L) Percentage of Myo7 $\mathrm{a}^{+\mathrm{ve}}$ cells that express LacZ in each founder line, normalized to the number of total Myo $7 \mathrm{a}^{+ \text {ve }}$ cells in the same region. Data are expressed as mean \pm S.E.M for an $n$ of 3-4. IHC, inner hair cells; OHC, outer hair cells. Scale bar: $50 \mu \mathrm{m}$.

specific to HCs with both lines having few $\mathrm{LacZ}^{+\mathrm{ve}} \mathrm{IPhCs}$ in the basal turn. There were also some $\mathrm{LacZ}^{+\mathrm{ve}}$ cells in the SGN region of the basal turn for F26. In F23, LacZ expression was specific to HCs only in the apical turn with a moderate amount of $\mathrm{LacZ}^{+\mathrm{ve}} \mathrm{IPhCs}$ and cells in the GER in the middle turn that increased in the basal turn. Lastly, F10 had some LacZ ${ }^{+v e}$ IPhCs and GER cells in all three cochlear turns, while F12 had an apical-to-basal gradient of increasing quantities of $\mathrm{LacZ}^{+\mathrm{ve}} \mathrm{IPhCs}$. In contrast to the consistent mCherry intensity, LacZ intensity varied from cell to cell across all founders (Figure 3F-J').

In Atoh1-rtTA; TetO-mCherry utricles, the percentage of total mCherry $^{+\mathrm{ve}}$ HCs were: $\mathrm{F} 7=78.2 \pm 0.6 \%, \mathrm{~F} 10=85.6 \pm 0.5 \%, \mathrm{~F} 12$ $=73.7 \pm 4.1 \%, \mathrm{~F} 23=48.6 \pm 6.4 \%$, and $\mathrm{F} 26=79.4 \pm 3.6 \%$ (mCherry $^{+\mathrm{ve}} \mathrm{HCs}$ expressed as a percentage of total HCs, $n=3$, Figure 4A-E, K). Several of the Atoh1-rtTA; TetO-mCherry founders showed a significant difference in the percentage of mCherry ${ }^{+v e} \mathrm{HCs}$

Table 1 | Summary of Atoh1-rtTA activity in non-hair cells of the cochlea

F7

TetO-mCherry Base $=$ Few GER, Base $=$ Few GER, Several IPhC

TetO-LacZ
F10 Several IPhC Apex, Middle, and Base = Few IPhC and GER
$\mathrm{F} 12$

Middle $=$ Few IPhC Base $=$ Moderate IPhC Apical to basal gradient of increasing IPhCs
F23

$\begin{array}{ll}\text { Base }=\text { Few GER, } & \text { N/A } \\ \text { Several IPhC } & \\ \text { Middle = Few IPhC } & \text { Base }=\text { Few IPhC, } \\ \text { and GER } & \text { Few SGC } \\ \text { Base }=\text { Moderate } & \\ \text { IPhC and GER } & \end{array}$



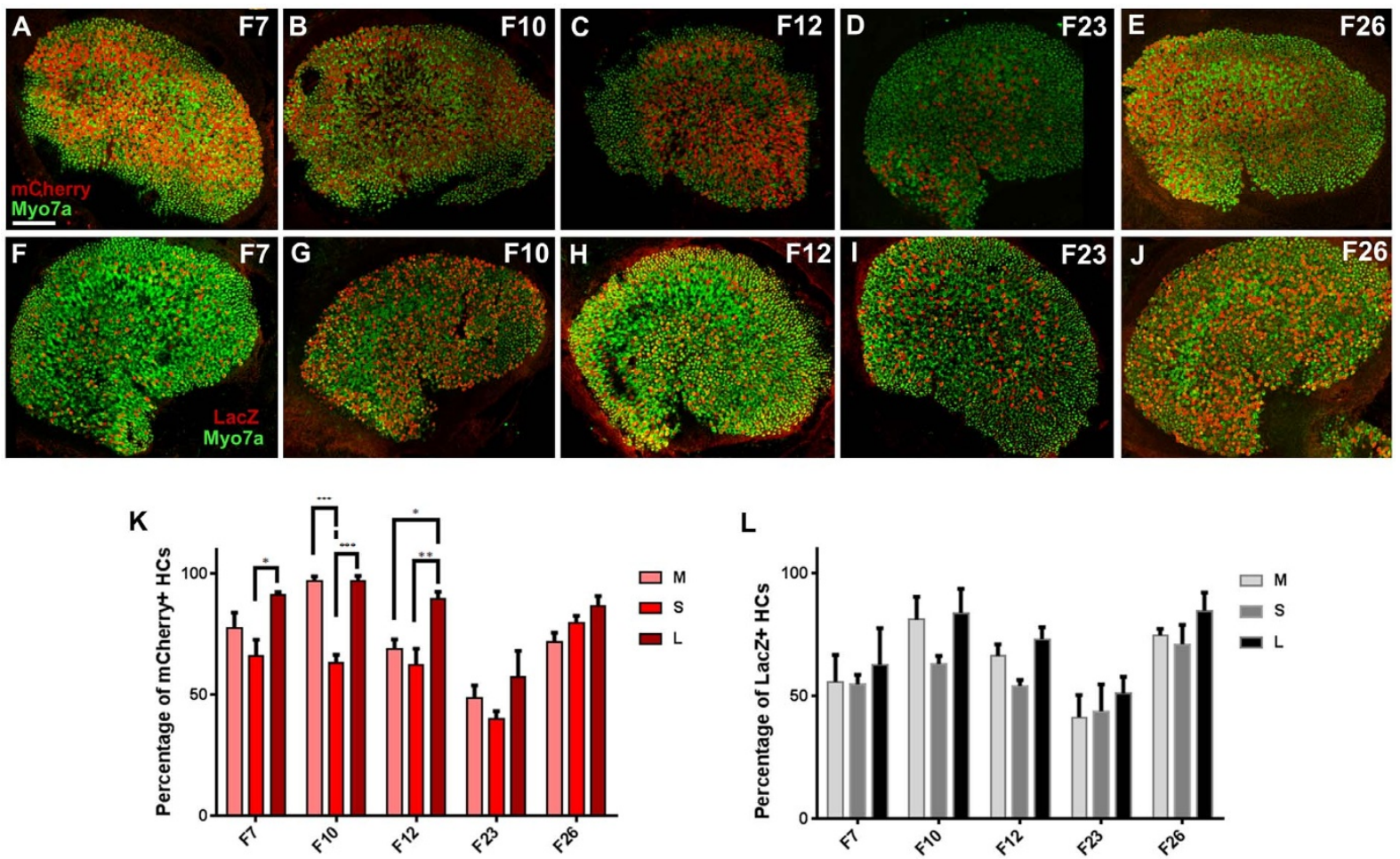

Figure $4 \mid$ Atoh1-rtTA activity in the utricle. (A-E) Representative confocal images of mCherry ${ }^{+v e}$ (red) cells and Myo7a-labeled HCs (green) in the utricle for each founder line breed with the TetO-mCherry reporter at P3. (F-J) Representative confocal images of LacZ ${ }^{+ \text {ve }}$ (red) cells and Myo7a-labeled $\mathrm{HCs}$ (green) in the utricle for each founder line breed with the TetO-LacZ reporter at P3. (K) Percentage of Myo7a ${ }^{+ \text {ve }}$ cells that express mCherry in utricular regions of each founder line, normalized to the number of total Myo7a ${ }^{+v e}$ cells in the same region. (L) Percentage of Myo7a ${ }^{+v e}$ cells that express $\mathrm{LacZ}$ in utricular regions of each founder line, normalized to the number of total Myo7a ${ }^{+v e}$ cells in the same region. Data are expressed as mean \pm S.E.M for an $n$ of 3. Statistical differences between regions were obtained using a two-way ANOVA followed by a Tukey's posthoc test. * $\mathrm{p}<0.05$, ${ }^{* *} \mathrm{p}<0.01$, *** $\mathrm{p}<0.001$. M, medial; S, striolar; L, lateral Scale bar: $100 \mu \mathrm{m}$.

in different regions of the utricle (Figure $4 \mathrm{~K})$. This included a difference between striolar and lateral regions in F7, F10, and F12 and a difference between medial and striolar regions in F10. All founders had varying numbers of mCherry ${ }^{+v e}$ SCs that were found across all regions of the utricle with F7 and F10 having the fewest and F12 having the most. Lastly, the mCherry intensity varied from cell to cell across all founders (Figure 4A-E). We also observed mCherry ${ }^{+v e}$ HCs in the lateral and superior cristae.

In contrast, fewer numbers of labeled cells were detected in Atoh1rtTA; TetO-LacZ utricles: $\mathrm{F} 7=57.7 \pm 9.9 \%, \mathrm{~F} 10=76.0 \pm 7.3 \%$, F12 $=64.5 \pm 0.6 \%, \mathrm{~F} 23=45.4 \pm 8.8 \%$, and F26 $=76.8 \pm 5.8 \%\left(\mathrm{LacZ}^{+\mathrm{ve}}\right.$ HCs expressed as a percentage of total HCs, $n=3$, Figure 4F-J, L). There was no significant difference in the number of $\mathrm{LacZ}^{+\mathrm{ve}} \mathrm{HCs}$ among utricular regions, however all founder lines had LacZ ${ }^{+v e}$ SCs with F7 and F26 having the fewest and F23 and F12 having the most. LacZ intensities also varied with all founders having a mosaic expression pattern throughout the utricle (Figure $4 \mathrm{~F}-\mathrm{J}$ ). We also observed $\mathrm{LacZ}^{+\mathrm{ve}} \mathrm{HCs}$ in the lateral and superior cristae.

During postnatal development of the cerebellum, Atoh1 is expressed in proliferating granule neuron precursors (GNPs) of the external granule layer ${ }^{5}$. We therefore assessed mCherry expression in cerebella of the five Atoh1-rtTA; TetO-mCherry transgenic lines at P3, after doxycycline treatment was administered from P0P3. We observed mCherry ${ }^{+v e}$ GNPs in all transgenic lines with F7, F12, and F26 having the most labeled cells (Figure $5 \mathrm{~A}-\mathrm{J}^{\prime}$ ). In uninduced negative controls, which did not receive doxycycline, no mCherry $^{\text {tve }}$ cells were observed in the cerebellum (Figure 5P-P'). This finding confirms that Atoh1-rtTA activity occurs in Atoh1expressing cells in the cerebellum. We also examined the rest of the brain and only observed mCherry ${ }^{+v e}$ cells in the hippocampus of F12, F23, and F26 (Figure 5K-O' $)$. No other brain region had mCherry expression. This misexpression of mCherry in the hippocampus of three founder lines matches the eGFP expression seen in Atoh1-eGFP mice which also use the Atoh1 enhancer element to drive expression of eGFP ${ }^{16}$. However Atoh1-eGFP mice have eGFP expression in the cortex which was not observed in our model ${ }^{16}$.

Additional control experiments were performed with Atoh1-rtTA mice of the F7 lineage which showed strong and consistent rtTA activity in cochlear and utricular HCs and was HC-specific in apical and middle turns of the cochlea. These included measuring transient expression of $\mathrm{TetO}$ reporters in inner ear tissues and the hearing ability of mice containing the newly generated Atoh1-rtTA allele.

The Tet-On system is designed to produce transient changes in gene expression since the rtTA protein can no longer bind to TetO and activate transcription once doxycycline is removed ${ }^{2,3}$. To measure transient effects in our system, we used Atoh1-rtTA mice of the F7 lineage bred with TetO-mCherry or TetO-LacZ reporter mice and administered doxycycline from $\mathrm{P} 0-\mathrm{P} 3$. The cochlea and utricle were analyzed at P7, P21, and 6 weeks of age. In Atoh1-rtTA ${ }^{+\mathrm{ve}}$; TetO$L a c Z^{+v e}$ mice, the majority of cochlear and utricular HCs retained expression of LacZ at all ages tested and no HC loss was detected (Figure 6A-B). A similar expression pattern of mCherry ${ }^{+v e} \mathrm{HCs}$ was seen in Atoh1-rtTA ${ }^{+\mathrm{ve}}$; TetO-mCherry ${ }^{+\mathrm{ve}}$ mice. However outer HC loss was detected at P21 which worsened at 6 weeks of age, but inner HCs and utricular HCs remained intact (Figure 6C-E). Since the TetOn system requires the presence of both the rtTA protein and doxycycline for gene expression to occur (Figure 1A) and the Atoh1-rtTA transgene we generated uses the Atoh1 enhancer element to drive expression of both rtTA and hPLAP (Figure 1B), we performed alkaline phosphatase staining in the cochlea and utricle at 6 weeks 

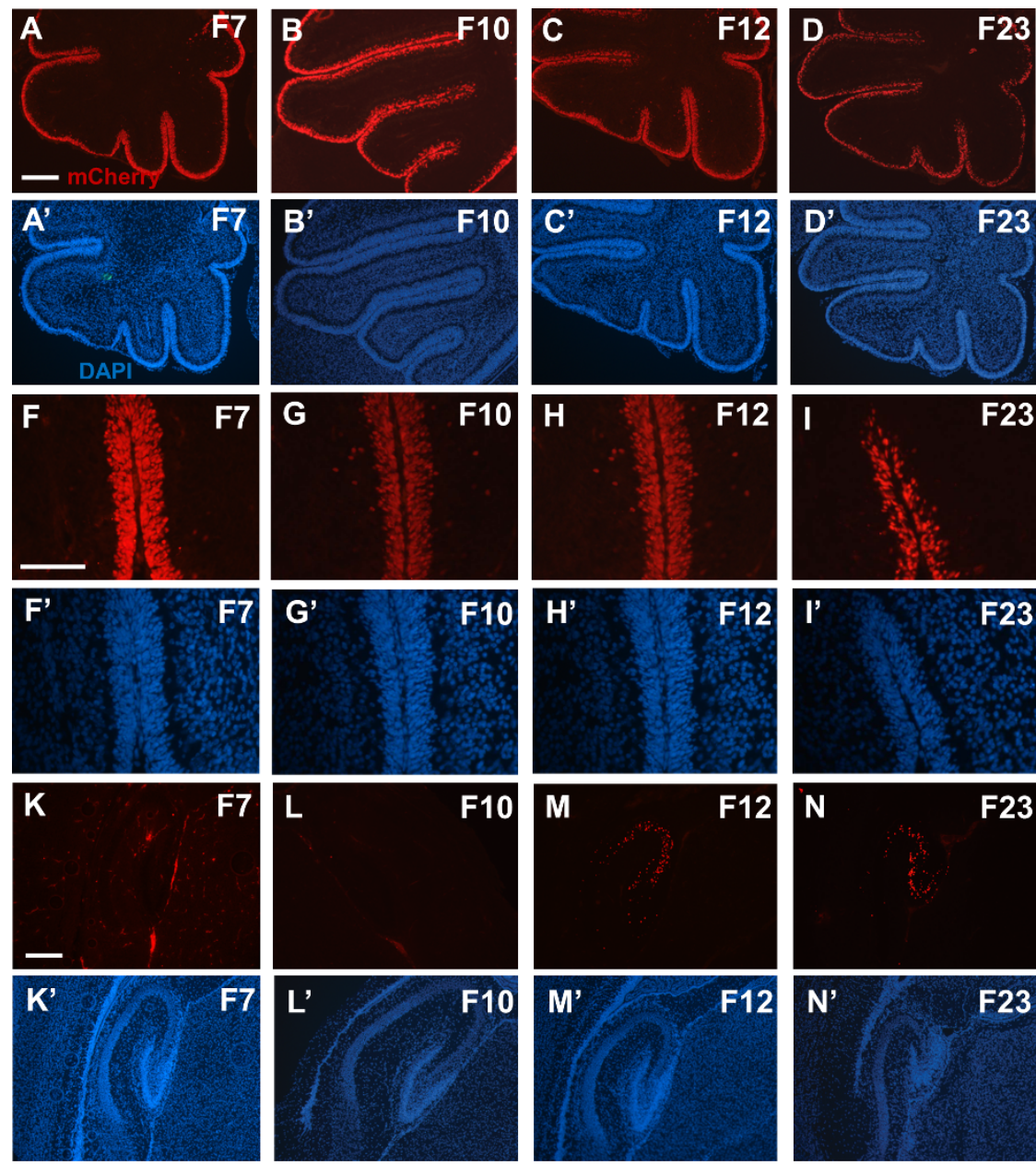
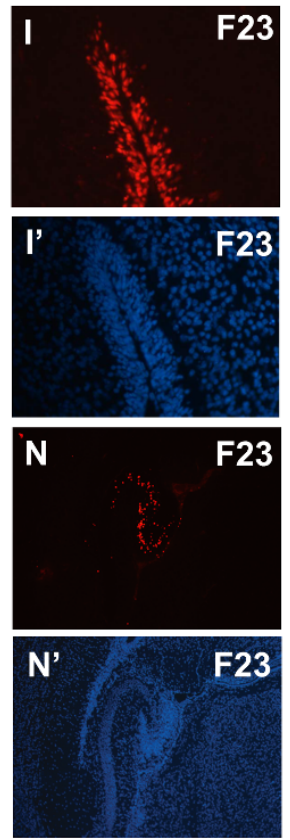
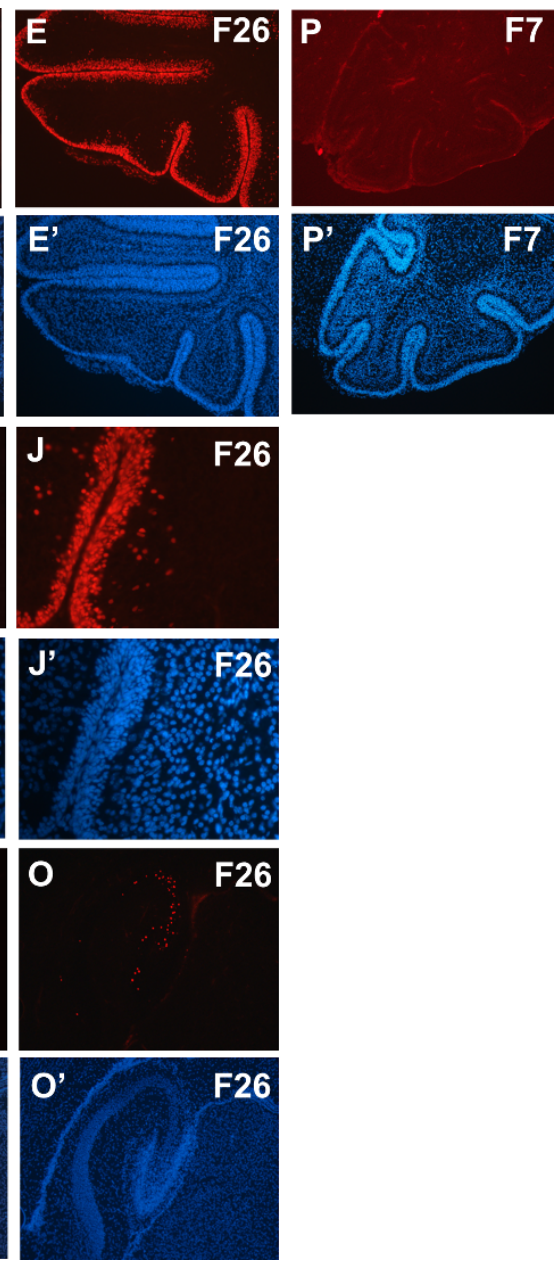

Figure $5 \mid$ Atoh1-rtTA activity in the cerebellum and hippocampus. Representative images of mCherry ${ }^{+ \text {ve }}($ red) cells in the cerebella (A-J') and hippocampus $\left(\mathrm{K}-\mathrm{O}^{\prime}\right)$ of each founder line at $\mathrm{P} 3$ after doxycycline administration from $\mathrm{P} 0-\mathrm{P} 3$. (P-P') un-induced control images of Atoh1-rtTA(F7) ${ }^{+ \text {ve }}$; TetO-LacZ ${ }^{+ \text {ve }}$ cerebella without doxycycline induction. Nuclei are labeled by DAPI (blue). Scale bars: $200 \mu \mathrm{m}$.

of age to determine whether expression of the transgene persists. Faint alkaline phosphatase staining was present in the utricle of Atoh1-rtTA ${ }^{+\mathrm{ve}}$ mice from the F7 lineage (Figure 6G) suggesting that the transgene is still expressed at 6 weeks of age. However no staining was observed in the cochlea (Figure 6F).

Finally we measured the hearing ability of Atoh1-rtTA mice using evoked auditory brainstem response (ABR) to investigate whether the Atoh1-rtTA transgene had any negative effects on cochlear function. ABR was performed on 3 month old Atoh1-rtTA ${ }^{+\mathrm{ve}}$; TetO$m$ Cherry $^{+v e}$ mice of the F7 lineage without administration of doxycycline and littermate controls that lacked both the $r t T A$ and $m$ Cherry alleles. There was no significant difference in ABR responses between groups at any of the frequencies tested (Figure 7). Thus we conclude that Atoh1-rtTA mice have normal hearing and the Atoh1-rtTA transgene had no effect on genes required for hearing function.

\section{Discussion}

We have created a new transgenic mouse model using the tetracycline-inducible system to target HCs in the inner ear and provided a thorough characterization of rtTA activity in five founder lines using two TetO-reporter alleles. Differences in rtTA activity among founders were expected since the Atoh1-rtTA mouse lines are transgenics. Thus each founder likely has a different insertion site and a different copy number of the transgene. In summary, F7, F10, F12, and F26 showed rtTA activity in the majority of cochlear HCs (94-99\% with TetO-mCherry and 77-85\% with TetO-LacZ), while
F23 was less robust, labeling $70 \%$ of HCs with TetO-mCherry and $64 \%$ with TetO-LacZ. F26 was the most specific to HCs, but had highly variable LacZ intensity levels which may suggest a lower level of rtTA expression. LacZ intensity levels were more robust in F7, F10, and F12, but Atoh1-rtTA activity was also detected in other cell types. F7 showed non-HC reporter expression only in the basal turn, while F10 and F12 labeled other cells in all turns of the cochlea. Therefore F7 provides strong and consistent rtTA activity in cochlear HCs and was HC-specific in apical and middle turns of the cochlea.

In control experiments for basal activity of the reporter lines and leakiness of the un-induced Atoh1-rtTA allele, there was a similar expression pattern of $\mathrm{mCherry}^{+\mathrm{ve}}$ cells in the SGN of the cochlea, mCherry $^{+v e}$ cells in the utricular stroma, as well as some $\mathrm{LacZ}^{+\mathrm{ve}} \mathrm{SCs}$ in the utricle. The presence of reporter ${ }^{+v e}$ cells in the absence of the rtTA protein has been reported previously in other organ systems ${ }^{15}$ and thus these reporter ${ }^{+\mathrm{ve}}$ cells can be ignored in the characterization of the founder lines since they are not related to Atoh1-rtTA. The TetO-mCherry and TetO-LacZ reporter lines are still useful to measure Atoh1-rtTA-driven activity since no HCs were labeled in the cochlea or utricle and only a few SCs were labeled by LacZ in the utricle. However we observed a small percentage of $\mathrm{LacZ}^{+\mathrm{ve}} \mathrm{HCs}$ in the medial region of the utricle in un-induced Atoh1-rtTA ${ }^{+\mathrm{ve}}$; TetO$\mathrm{LacZ}^{+\mathrm{ve}}$ mice from the founder 7 lineage suggesting that a few utricular HCs can express LacZ without doxycycline. Yet no labeled HCs were observed when the TetO-mCherry reporter was used in uninduced negative control experiments. Taken together this data 

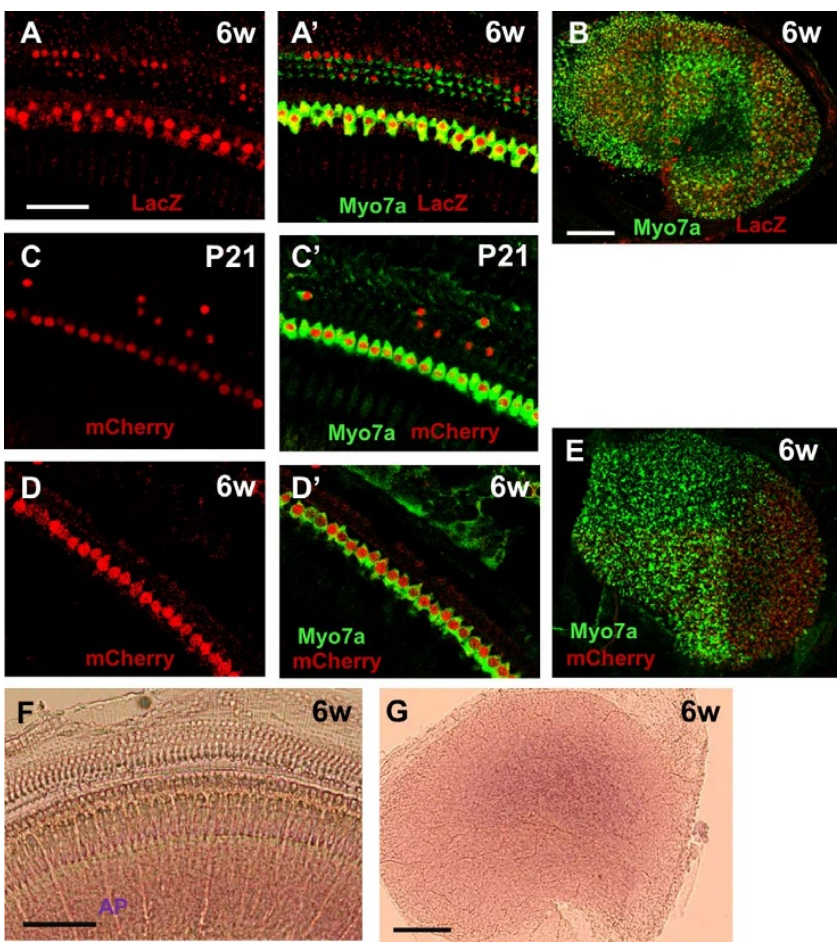

Figure 6 | TetO-reporter expression was still present at 6 weeks of age. Representative confocal images of $\mathrm{LacZ}^{+\mathrm{ve}}$ (red) cells in the middle cochlear turn (A) and utricle (B) of Atoh1-rtTA(F7) ${ }^{+v e}$; TetO-Lac $Z^{+ \text {ve }}$ mice at 6 weeks of age after doxycycline treatment ended at $\mathrm{P} 3$. (A') is a merged image with HCs labeled by myosin VIIa (Myo7a, green). Representative confocal images of mCherry $^{+\mathrm{ve}}$ (red) cells in the middle cochlear turn of Atoh1-rtTA(F7) ${ }^{+\mathrm{ve}}$; TetO- $m$ Cherry $^{+v e}$ mice at P21 (C) and 6 weeks of age (D) and in the utricle at 6 weeks of age (E) after doxycycline treatment ended at P3. (C', D') are merged images with HCs labeled by myosin VIIa (Myo7a, green).

Representative alkaline phosphatase (AP) staining images at 6 weeks of age in the cochlea (F) and utricle $(\mathrm{G})$ of Atoh1-rtTA mice from the F7 lineage. Scale bars: $50 \mu \mathrm{m}$ in $\left(\mathrm{A}-\mathrm{A}^{\prime}\right),(\mathrm{C}-\mathrm{D})$ and $100 \mu \mathrm{m}$ in $(\mathrm{B}, \mathrm{E}-\mathrm{G})$.

illustrates the importance of using more than one reporter line to characterize a new Tet-On mouse line.

In the cochlea, several founder lines showed mCherry or LacZ expression in cells other than HCs including IPhCs and cells in the GER. This may have been caused by a low level of Atoh1 expression when doxycycline was administered or by transgene insertion effects. Others have shown that Atoh1 is expressed in SCs, although this expression becomes undetectable by embryonic day $17^{17,18}$. Therefore, some IPhCs at $\mathrm{P} 0-\mathrm{P} 3$ may still have Atoh1 expression that is below the level of detection. However the cochlea matures in a gradient from base to ape $\mathrm{x}^{19-22}$ with Atoh 1 expression persisting for the longest period of time in the apex. In contrast we observed more mCherry $^{+\mathrm{ve}}$ and $\mathrm{LacZ}^{+\mathrm{ve}}$ IPhCs in middle and basal turns which does not match this pattern. In addition not all founder lines showed mCherry ${ }^{+v e}$ IPhCs with the same doxycycline induction paradigm. Thus a more likely explanation is that local regulatory elements located near the Atoh1-rtTA transgene insertion site could have caused expression of rtTA in IPhCs.

In addition several of the founders showed a significant difference in the percentage of mCherry ${ }^{+\mathrm{ve}} \mathrm{HCs}$ in different regions of the utricle. These regional differences may have been caused by differences in the timing of cell cycle exit and subsequent HC differentiation ${ }^{23}$, by differences in postnatal addition of HCs among regions ${ }^{24}$, or by transgene insertion effects. However no regional differences were observed when using the TetO-LacZ reporter making transgene insertion effects the most likely explanation. Similarly three of the five founder lines had mCherry $^{+ \text {ve }}$ cells in the hippocampus where Atoh1 is not normally

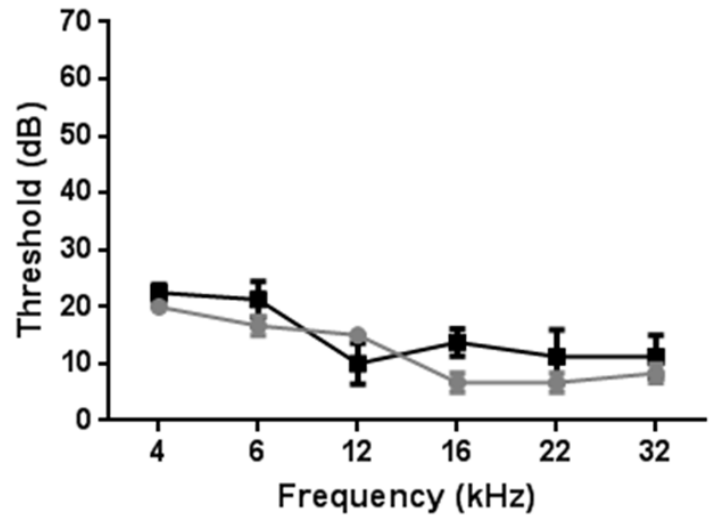

Figure $7 \mid$ Hearing ability of Atoh1-rtTA(F7) mice. ABR was performed on 3 month old Atoh1-rtTA(F7) ${ }^{+ \text {ve }}$; TetO-mCherry ${ }^{+v e}$ mice without administration of doxycycline (grey circles) and littermate controls that lacked both the $r t T A$ and $m$ Cherry alleles (black squares). Data are expressed as mean \pm S.E.M for an $n$ of 3-4. There were no statistical differences between groups.

expressed. This was also observed in the Atoh1-eGFP transgenic line ${ }^{16}$ and was likely caused by transgene insertion effects.

Since the tetracycline-inducible system is designed to produce transient changes in gene expression and the half-life of LacZ is 24-48 hours in mammalian cells ${ }^{25}$, it is surprising that both reporters remained robustly expressed at 6 weeks of age when doxycycline treatment ended at P3. (The half-life of mCherry is unknown.) The Tet-On system requires the presence of both the rtTA protein and doxycycline for expression of TetO-driven genes. Others have demonstrated that endogenous Atoh 1 is rapidly downregulated in the inner ear during the first postnatal week ${ }^{4}$. However expression of eGFP was observed in cochlear HCs at 6 weeks of age in the Atoh1$e G F P$ mouse ${ }^{26}$ which uses the same Atoh 1 enhancer element to drive expression of eGFP as our Atoh1-rtTA transgene. Using alkaline phosphatase staining, we detected weak expression of the Atoh1$r t T A$ transgene in utricular HCs at 6 weeks of age, but not in cochlear HCs. In the Atoh1-rtTA transgene, hALAP expression is controlled by IRES-mediated translation while rtTA expression is controlled by 5' cap-dependent translation. Others have shown that IRESmediated translation is less efficient ${ }^{27}$ thus it is possible that rtTA is expressed in cochlear HCs when hALAP is below the level of detection. Another possible explanation for the persistent expression of the TetO-reporters is that the rtTA/doxycycline/TetO complex may be very stable and resistant to degradation.

In support of our findings for persistent TetO-reporter expression, a Sox10-rtTA allele was recently characterized in the inner ear using the TetO-LacZ reporter and $\mathrm{LacZ}$ expression was also observed at 8 weeks of age after cessation of doxycycline treatment at $\mathrm{P} 2{ }^{28}$. Analogous to the blood-brain barrier, the blood-labyrinth barrier functions to protect the inner ear from substances circulating in the blood. Since the blood-labyrinth barrier develops in rodents during the first two postnatal weeks ${ }^{29}$, it is possible that a large amount of doxycycline entered the cochlear and vestibular systems before it was formed and then became trapped. In addition doxycycline is heavily protein bound $(>90 \%)^{30}$ which could contribute to a long half-life in inner ear tissues and other drugs have been shown to remain in the inner ear for a much longer time than in serum, brain, or other organs $^{31}$. In support of our hypothesis, doxycycline treatment administered at P14 failed to induce rtTA-driven gene expression in the inner ear using the Rosa26-loxP-stop-loxP-rtTA-IRES-eGFP mouse line $^{32}$. While the Sox10-rtTA model showed decreased rtTA-driven activity when doxycycline was administered at P14, no effect was observed at P28 unless doxycycline was combined with the loop diuretic furosemide, which alters the properties of the blood-laby- 
rinth barrier $^{28}$. In addition others have shown that tetracycline, which is structurally similar to doxycycline, cannot cross the blood-brain barrier ${ }^{31}$. Taken together, these data suggest that doxycycline has limited ability to cross the blood-labyrinth barrier and supports our hypothesis that the persistent expression of rtTA-driven reporter expression in Atoh1-rtTA mice is caused by sequestration of doxycycline in inner ear tissues. In light of our observations, it is uncertain whether transient gene expression occurred when other $r t T A$ alleles were used in inner ear studies such as the Rosa26-loxP-stop-loxP-rtTA-IRES-eGFP allele ${ }^{32-34}$ and the Pax2$r t T A$ allele ${ }^{35}$. To determine if similar long lasting effects occur, each rtTA allele should be tested with a TetO-reporter line specifically in inner ear tissues using the same doxycycline induction paradigm used in experimental studies.

It was also surprising that outer HC loss occurred in Atoh1$r t T A^{+v e}$; TetO-mCherry ${ }^{+ \text {ve }}$ mice at P21 and 6 weeks of age. Outer HCs are known to be more susceptible to death than inner HCs when exposed to multiple types of insults including noise or ototoxic drugs $^{36-40}$. However to our knowledge the death of outer HCs by expression of a reporter gene has not been previously reported. This cell death may have occurred due to a large amount of mCherry mRNA or protein that accumulated in the cell between P3 and P21 which overwhelmed the transcriptional/translational machinery at the detriment of genes required for outer HC survival. Alternatively the mCherry protein could directly induce cell death pathways in outer HCs. In addition, in the TetO-mCherry allele, $m$ Cherry was knocked into the endogenous Colla1 locus ${ }^{12}$ and thus only one copy of Colla1 is expressed which may contribute to the outer HC death we observed. However no outer HC loss was observed in TetO-mCherry mice without doxycycline induction at 3 months of age as demonstrated by the normal ABR measurements we obtained. Thus one copy of Colla1 is not toxic but the combination of one copy of Colla1 with mCherry expression could be.

In conclusion, the Atoh1-rtTA mouse produces rtTA activity in the majority of HCs in the cochlea and utricle and in GNP cells of the cerebellum during neonatal ages. Therefore it is a valuable tool for future experiments especially when used in combination with existing Cre and CreER mouse models to modulate expression of multiple genes in two distinct cell types or in the same cell type at different times. While transient control of gene expression was not achieved with the Atoh1-rtTA mouse model, this is likely a property of the inner ear's inability to remove doxycycline efficiently and has implications for other tetracycline-inducible mouse models used in inner ear research. Our studies also highlight potential problems with long term expression of the mCherry reporter in outer HCs.

\section{Methods}

Generation of Atoh1-rtTA transgenic mice. The Atoh1-CreER-IRES-hPLAP-SV40polyA construct ${ }^{8}$ was modified to replace the CreER sequence with a Tet-On $3 G$ rtTA sequence (Clontech, cat\# 631159). Founder lines were obtained and Southern blot was performed as previously described ${ }^{8}$. Briefly, Southern blot analysis used the XbaI restriction enzyme and a probe that recognizes the Atohl enhancer sequence. Genotyping primers were designed with the forward primer in the Atohl enhancer element and the reverse primer in the $r t T A$ sequence $\left(5^{\prime}\right.$

TCGTCAAGGGCGTCGGTCGGC 3' and 5' CTGGCAGAGGCTCCTGGCC $33^{\prime}$ ).

Characterization of Atoh1-rtTA transgenic mice. Expression of the transgene was detected at P0 using alkaline phosphatase staining (NBT/BCIP ready to use tablets (Roche cat\#11697471001)). Temporal bones were post-fixed for 1 hour in 4\% paraformaldehyde, then transferred to $10 \mathrm{mM}$ PBS. After dissection, samples were heated at $65^{\circ} \mathrm{C}$ for 1 hour in $10 \mathrm{mM}$ PBS then cooled to room temperature before the addition of the alkaline phosphatase staining reagent (1 NBT/BCIP tablet dissolved in $10 \mathrm{ml}$ double-distilled water). The enzymatic reaction occurred at room temperature in the dark for 30 to 90 minutes followed by washes in PBS and mounting to slides.

To characterize rtTA activity, we bred five founder lines with two different TetOreporter lines: TetO-mCherry (The Jackson Laboratory, stock \#14592) and TetO-lacZ (The Jackson Laboratory, stock \#2621). TetO reporter expression was induced with doxycycline administered in the food $(2000 \mathrm{mg} / \mathrm{kg}$, Harlan Laboratories) to the nursing mother from P0-P3 as well as an injection of doxycycline $(100 \mathrm{mg} / \mathrm{kg}$, intraperitoneal (IP), Fisher) administered to the pups at P1. Samples were collected at P3 and post-fixed overnight in $4 \%$ paraformaldehyde. Routine immunostaining procedures $^{41}$ were used with the following primary antibodies: anti- $\beta$ gal $(1: 500$, cat \#AB9361 Abcam) and anti-myosin VIIa (1:200, cat \#25-6790 Proteus BioSciences). All secondary antibodies were Alexa-conjugated from Invitrogen and were used at a $1: 1000$ dilution. mCherry was directly visualized on $12 \mu \mathrm{m}$ brain cryosections stained with DAPI ( $1: 1000$, Invitrogen). Images of the cochlea and utricle were taken using a Zeiss LSM 700 or a Leica SP5 confocal microscope. Images of the brain were taken using a Zeiss Axioskop 2 plus with an AxioCanHRc camera. All animal work was performed in accordance with the guidance and approval from the Institutional Animal Care and Use Committee at St. Jude Children's Research Hospital and Southern Illinois University, School of Medicine.

Quantification. Inner ear HCs were identified by myosin VIIa labeling. In the cochlea, the number of $\mathrm{LacZ}^{+\mathrm{ve}} \mathrm{HCs}$ was counted in two, $200 \mu \mathrm{m}$ regions, randomly chosen from each cochlear turn. Since the mCherry reporter had more robust expression, the entire cochlea was scanned and mCherry negative HCs were counted. For the utricle, the number of labeled HCs in $50 \mu \mathrm{m} \times 50 \mu \mathrm{m}$ squares was counted at nine locations spaced along the anterior/posterior axis of the medial, striolar, and lateral regions as previously described ${ }^{42}$. Reporter ${ }^{+ \text {ve }}$ cells were averaged across turns or utricle regions and expressed as a percentage of total HCs per organ. The $n$ value throughout the paper refers to one ear per animal.

Auditory Brainstem Response. Mice were anesthetized using Avertin $(600 \mathrm{mg} / \mathrm{kg}$, IP) and ABR was performed as previously described ${ }^{41}$

Statistical Analysis. All data are presented as mean \pm S.E.M. Statistical analyses were performed using Graphpad Prism 6.02 (Graphpad Software Inc.). Comparison of labeled HCs from different groups (i.e. inner vs. outer HCs, across cochlear turns, and among utricle regions) and $\mathrm{ABR}$ threshold values across frequencies were determined using a two-way ANOVA followed by either Sidak's or Tukey's multiple comparisons test.

1. Cox, B. C., Liu, Z., Lagarde, M. M. \& Zuo, J. Conditional gene expression in the mouse inner ear using Cre-loxP. J Assoc Res Otolaryngol 13, 295-322 (2012).

2. Gossen, M. et al. Transcriptional activation by tetracyclines in mammalian cells. Science 268, 1766-1769 (1995).

3. Mansuy, I. M. et al. Inducible and reversible gene expression with the rtTA system for the study of memory. Neuron 21, 257-265 (1998).

4. Bermingham, N. A. et al. Math1: an essential gene for the generation of inner ear hair cells. Science 284, 1837-1841 (1999).

5. Ben-Arie, N. et al. Math1 is essential for genesis of cerebellar granule neurons. Nature 390, 169-172 (1997).

6. Helms, A. W., Abney, A. L., Ben-Arie, N., Zoghbi, H. Y. \& Johnson, J. E. Autoregulation and multiple enhancers control Math1 expression in the developing nervous system. Development 127, 1185-1196 (2000).

7. Matei, V. et al. Smaller inner ear sensory epithelia in Neurog 1 null mice are related to earlier hair cell cycle exit. Dev Dyn 234, 633-650 (2005).

8. Chow, L. M. et al. Inducible Cre recombinase activity in mouse cerebellar granule cell precursors and inner ear hair cells. Dev Dyn 235, 2991-2998 (2006).

9. Machold, R. \& Fishell, G. Math1 is expressed in temporally discrete pools of cerebellar rhombic-lip neural progenitors. Neuron 48, 17-24 (2005).

10. Chen, P., Johnson, J. E., Zoghbi, H. Y. \& Segil, N. The role of Math1 in inner ear development: Uncoupling the establishment of the sensory primordium from hair cell fate determination. Development 129, 2495-2505 (2002).

11. Jacques, B. E., Montcouquiol, M. E., Layman, E. M., Lewandoski, M. \& Kelley, M. W. Fgf8 induces pillar cell fate and regulates cellular patterning in the mammalian cochlea. Development 134, 3021-3029 (2007).

12. Egli, D., Rosains, J., Birkhoff, G. \& Eggan, K. Developmental reprogramming after chromosome transfer into mitotic mouse zygotes. Nature 447, 679-685 (2007).

13. Hochedlinger, K., Yamada, Y., Beard, C. \& Jaenisch, R. Ectopic expression of Oct4 blocks progenitor-cell differentiation and causes dysplasia in epithelial tissues. Cell 121, 465-477 (2005).

14. Rizzo, M. A., Davidson, M. W. \& Piston, D. W. Fluorescent protein tracking and detection: applications using fluorescent proteins in living cells. Cold Spring Harb Protoc 2009, pdb top64 (2009).

15. Furth, P. A. et al. Temporal control of gene expression in transgenic mice by a tetracycline-responsive promoter. Proc Natl Acad Sci U S A 91, 9302-9306 (1994)

16. Lumpkin, E. A. et al. Math1-driven GFP expression in the developing nervous system of transgenic mice. Gene Expr Patterns 3, 389-395 (2003).

17. Yang, H., Xie, X., Deng, M., Chen, X. \& Gan, L. Generation and characterization of Atoh1-Cre knock-in mouse line. Genesis 48, 407-413 (2010).

18. Driver, E. C., Sillers, L., Coate, T. M., Rose, M. F. \& Kelley, M. W. The Atoh1lineage gives rise to hair cells and supporting cells within the mammalian cochlea. Dev Biol 376, 86-98 (2013).

19. Hallworth, R., McCoy, M. \& Polan-Curtain, J. Tubulin expression in the developing and adult gerbil organ of Corti. Hear Res 139, 31-41 (2000).

20. Jensen-Smith, H. C., Eley, J., Steyger, P. S., Luduena, R. F. \& Hallworth, R. Cell type-specific reduction of beta tubulin isotypes synthesized in the developing gerbil organ of Corti. J Neurocytol 32, 185-197 (2003).

21. Legendre, K., Safieddine, S., Kussel-Andermann, P., Petit, C. \& El-Amraoui, A. alphaII-betaV spectrin bridges the plasma membrane and cortical lattice in the lateral wall of the auditory outer hair cells. J Cell Sci 121, 3347-3356 (2008). 
22. Lelli, A., Asai, Y., Forge, A., Holt, J. R. \& Geleoc, G. S. Tonotopic gradient in the developmental acquisition of sensory transduction in outer hair cells of the mouse cochlea. J Neurophysiol 101, 2961-2973 (2009).

23. Jiang, T. in Association for Research in Otolaryngology 37th Annual Midwinter Meeting (San Diego, CA, 2014)

24. Burns, J. C., On, D., Baker, W., Collado, M. S. \& Corwin, J. T. Over half the hair cells in the mouse utricle first appear after birth, with significant numbers originating from early postnatal mitotic production in peripheral and striolar growth zones. J Assoc Res Otolaryngol 13, 609-627 (2012).

25. Smith, R. L., Geller, A. I., Escudero, K. W. \& Wilcox, C. L. Long-term expression in sensory neurons in tissue culture from herpes simplex virus type 1 (HSV-1) promoters in an HSV-1-derived vector. J Virol 69, 4593-4599 (1995).

26. Liu, Z. et al. Age-dependent in vivo conversion of mouse cochlear pillar and Deiters' cells to immature hair cells by Atoh1 ectopic expression. J Neurosci 32, 6600-6610 (2012).

27. Kazadi, K. et al. Genomic determinants of the efficiency of internal ribosomal entry sites of viral and cellular origin. Nucleic Acids Res 36, 6918-6925 (2008).

28. Walters, B. J. \& Zuo, J. in 36th Annual MidWinter Meeting of the Association for Research in Otolaryngology (Baltimore, MD, 2013).

29. Suzuki, M., Yamasoba, T. \& Kaga, K. Development of the blood-labyrinth barrier in the rat. Hear Res 116, 107-112 (1998).

30. Bidgood, T. L. \& Papich, M. G. Comparison of plasma and interstitial fluid concentrations of doxycycline and meropenem following constant rate intravenous infusion in dogs. Am J Vet Res 64, 1040-1046 (2003).

31. Stupp, H., Kupper, K., Lagler, F., Sous, H. \& Quante, M. Inner ear concentrations and ototoxicity of different antibiotics in local and systemic application. Audiology 12, 350-363 (1973).

32. Kelly, M. C., Chang, Q., Pan, A., Lin, X. \& Chen, P. Atoh1 directs the formation of sensory mosaics and induces cell proliferation in the postnatal mammalian cochlea in vivo. J Neurosci 32, 6699-6710 (2012).

33. Pan, W. et al. Ectopic expression of activated notch or SOX2 reveals similar and unique roles in the development of the sensory cell progenitors in the mammalian inner ear. J Neurosci 33, 16146-16157 (2013).

34. Pan, W., Jin, Y., Stanger, B. \& Kiernan, A. E. Notch signaling is required for the generation of hair cells and supporting cells in the mammalian inner ear. Proc Natl Acad Sci U S A 107, 15798-15803 (2010).

35. Burger, A., Koesters, R., Schafer, B. W. \& Niggli, F. K. Generation of a novel rtTA transgenic mouse to induce time-controlled, tissue-specific alterations in Pax2expressing cells. Genesis 49, 797-802 (2011).

36. Stebbins, W. C., Hawkins, J. E., Jr., Johnson, L. G. \& Moody, D. B. Hearing thresholds with outer and inner hair cell loss. Am J Otolaryng 1, 15-27 (1979).

37. Rydmarker, S. \& Nilsson, P. Effects on the inner and outer hair cells. Acta Otolaryngol Supp 441, 25-43 (1987).

38. Sha, S. H., Taylor, R., Forge, A. \& Schacht, J. Differential vulnerability of basal and apical hair cells is based on intrinsic susceptibility to free radicals. Hear Res 155, 1-8 (2001).

39. Li, G. et al. Salicylate protects hearing and kidney function from cisplatin toxicity without compromising its oncolytic action. Lab Invest 82, 585-596 (2002).
40. Oesterle, E. C., Campbell, S., Taylor, R. R., Forge, A. \& Hume, C. R. Sox2 and JAGGED1 expression in normal and drug-damaged adult mouse inner ear. J Assoc Res Otolaryngol 9, 65-89 (2008).

41. Mellado Lagarde, M. M. et al. Selective ablation of pillar and deiters' cells severely affects cochlear postnatal development and hearing in mice. J Neurosci 33, 1564-1576 (2013).

42. Burns, J. C., Cox, B. C., Thiede, B. R., Zuo, J. \& Corwin, J. T. In vivo proliferative regeneration of balance hair cells in newborn mice. J Neurosci 32, 6570-6577 (2012).

\section{Acknowledgments}

We thank Suzanne Baker, Shelly Wilkerson, and Kristen Correia (St. Jude Children's Research Hospital) for the Atoh1-CreER-IRES-hPLAP-SV40-polyA construct, for sectioning and staining the mouse brains, and for assistance with microinjection of the transgene, respectively. This work was supported in part by grants from the National Institute of Health (DC006471 (JZ), DC010310 (BCC), CA096832 (MFR), and Cancer Center Core Grant P30CA21765 (JZ, MFR)); the Office of Naval Research (N000140911014 (JZ), N000141210191 (JZ), N000141210775 (JZ), and N000141310569 (BCC)); and the American Lebanese Syrian Associated Charities (ALSAC) of St. Jude Children's Research Hospital. J. Zuo is a recipient of The Hartwell Individual Biomedical Research Award. The Southern Illinois University School of Medicine Research Imaging facility equipment was supported by Award Number S10RR027716 from the National Center for Research Resources-Health.

\section{Author contributions}

B.C.C., J.A.D., F.Z., M.F.R. and J.Z. developed the approach; B.C.C., J.A.D., J.B. and F.Z performed experiments and data analysis; B.C.C., J.B., F.Z., M.F.R. and J.Z. wrote or edited the manuscript text. All authors reviewed the manuscript prior to submission.

\section{Additional information}

Competing financial interests: The authors declare no competing financial interests.

How to cite this article: Cox, B.C. et al. Generation of Atoh1-rtTA transgenic mice: a tool for inducible gene expression in hair cells of the inner ear. Sci. Rep. 4, 6885; DOI:10.1038/ srep06885 (2014).

This work is licensed under a Creative Commons Attribution-NonCommercialShareAlike 4.0 International License. The images or other third party material in this article are included in the article's Creative Commons license, unless indicated otherwise in the credit line; if the material is not included under the Creative Commons license, users will need to obtain permission from the license holder in order to reproduce the material. To view a copy of this license, visit http:// creativecommons.org/licenses/by-nc-sa/4.0/ 